\title{
Characterization of a CD38-like 78-Kilodalton Soluble Protein Released from B Cell Lines Derived from Patients With X-linked Agammaglobulinemia
}

\author{
Roberto Mallone, ${ }^{*}$ Stefania Ferrua, ${ }^{*}$ Massimo Morra, ${ }^{*}$ Elena Zocchi, ${ }^{\ddagger}$ Kapil Mehta, ${ }^{\S}$ Luigi D. Notarangelo, \\ and Fabio Malavasi ${ }^{\star \star}$ \\ * Laboratory of Cell Biology, Department of Genetics, Biology, and Biochemistry, University of Torino, 10126 Torino, Italy; ${ }^{\ddagger}$ Institute of \\ Biochemistry, University of Genova, 16132 Genova, Italy; ${ }^{\S}$ Department of Bioimmunotherapy, The University of Texas M.D. Anderson \\ Cancer Center, Houston, Texas 77030; "Department of Pediatrics, University of Brescia, 25123 Brescia, Italy; and "Institute of Biology and \\ Genetics, University of Ancona Medical School, 60131 Ancona, Italy
}

\begin{abstract}
Studies on murine B lymphocytes showed that Bruton's tyrosine kinase mediates signal transduction induced via CD38, a nonlineage-restricted $45-\mathrm{kD}$ ectoenzyme. This signaling is defective in $\mathrm{B}$ cells from $\mathrm{X}$-linked immunodeficient mice affected with the analogue of human X-linked agammaglobulinemia (XLA). We performed a structural and functional analysis of CD38 in XLA and other immunodeficiencies, using EBV-immortalized B cells derived from such patients. Membrane CD38 was not significantly different from controls in structure, epitope density, enzymatic activity, and internalization upon binding of agonistic mAbs. Meanwhile, an increased release of soluble CD38 from XLA cells was observed: immunoprecipitation from XLA culture media yielded a protein of $\sim 78 \mathrm{kD}(\mathrm{p} 78)$, reacting also in Western blot and displaying both enzymatic activities and a peptide map similar to membrane CD38. Soluble forms and homotypic aggregations of CD38 were documented in different cell models and by crystallographic analysis of the Aplysia ADP-ribosyl cyclase, the ancestor of human CD38. p78 might represent the product of an altered turn-over of membrane CD38, a starting point for studying its association with Bruton's tyrosine kinase and its role in XLA and other B cell immunodeficiencies. (J. Clin. Invest. 1998. 101: 2821-2830.) Key words: CD38 • immunodeficiency • ADPribosyl cyclase $\bullet$ ectoenzyme $\bullet$ soluble receptor
\end{abstract}

\section{Introduction}

Human CD38 is a 45-kD type II glycoprotein expressed in different lineages at various stages of differentiation (1). Binding of the CD38 molecule by selected agonistic mAbs is followed by delivery of activation and proliferation signals (2), probably mimicking the interactions occurring physiologically with natural ligand(s) $(3,4)$; one of these ligands has been recently identified as CD31 (5). The description of these features of a

Address correspondence to Dr. Fabio Malavasi, Laboratorio Biologia Cellulare, Dip. Genetica, Biologia e Biochimica, Via Santena 19, 10126 Torino, Italy. Phone: 39-11-696-1734; FAX: 39-11-696-6155; E-mail: malavasi@molinette.unito.it

Received for publication 30 June 1997 and accepted in revised form 14 April 1998.

J. Clin. Invest.

(C) The American Society for Clinical Investigation, Inc. 0021-9738/98/06/2821/10 \$2.00

Volume 101, Number 12, June 1998, 2821-2830

http://www.jci.org surface receptor ruling cell to cell interactions was enriched recently by the finding that the extracellular domain of the protein bears a catalytic site able to convert $\mathrm{NAD}^{+}$to nicotinamide and cyclic adenosine diphosphate ribose (cADPR $)^{1}$ (cyclase activity) and, simultaneously, cADPR to ADPR (hydrolase activity) (6). Therefore, human CD38 is an ectoenzyme with peculiar catalytic activities, which result in the synthesis of a product involved in the regulation of cytoplasmic $\mathrm{Ca}^{2+}$ currents (7). Further complexity beyond this topological paradox is encountered when one considers the notion that surface CD38 may exist in a soluble form of $\sim 39 \mathrm{kD}(\mathrm{p} 39)$, detectable in in vitro models and in vivo biological fluids from normal or disease conditions (8). In contrast, there is ample evidence that in certain conditions, for instance in vitro upon $\mathrm{mAb}$ or ligand binding, the molecule can undergo internalization rather than shedding (9). Furthermore, there are also reports on lateral homotypic and heterotypic organization of the molecule. Indeed, Umar et al. described a high-molecular weight form of CD38, namely p190, on all-trans-retinoic acid (ATRA)-induced HL60 cells (10), known to overexpress CD38 upon ATRA treatment (11). Oligomerization processes also take place on erythrocyte membranes, either induced by $\mathrm{NAD}^{+}$or GSH (12).

A link between selected diseases (e.g., leukemia and myeloma, Alzheimer's disease, and AIDS [among others]) and CD38 expression and function has been sought with the aim of defining diagnostic and possibly therapeutic markers on one hand and, on the other, of helping to throw light on the functions exerted by the molecule in vivo (13). Interest in B cell immunodeficiencies stems from functional studies on X-linked immunodeficiency (xid) syndrome, the murine analogue of X-linked agammaglobulinemia (XLA), both diseases sharing molecular defects involving Bruton's tyrosine kinase (btk) (14). Mouse btk is an integral component of the CD38 transduction pathway: CD38 ligation not only induces btk phosphorylation, but also triggers proliferation and activation signals on normal murine B cells. None of these effects is seen on B cells obtained from xid mice, in spite of unaltered membrane CD38 levels (15-17).

Currently, not much information is available on altered CD38 expression and function in human congenital immunodeficiencies. This study reports that expression, enzymatic activities, and internalization of membrane CD38 are apparently unaltered in immunodeficient B cells; however, XLA cells are

1. Abbreviations used in this paper: ATRA, all-trans-retinoic acid; btk, Bruton's tyrosine kinase; cADPR, cyclic adenosine diphosphate ribose; cGDPR, cyclic guanine diphosphate ribose; ${ }^{125} \mathrm{I}$-IB $4,{ }^{125} \mathrm{I}$-labeled IB4; $\mathrm{NGD}^{+}$, nicotinamide guanine dinucleotide; PE, phycoerythrin; xid, X-linked immunodeficient; XLA, X-linked agammaglobulinemia. 
marked by the release of a 78-kD molecule (p78) that shares structural and functional homologies with membrane CD38. The finding of a soluble and active form of a CD38-like structure may reflect either a qualitative or quantitative defect in CD38 turnover, possibly playing an accessory role in the pathogenesis of selected immunodeficiencies involving the $\mathrm{B}$ compartment.

\section{Methods}

Cell lines. Continuous lymphoblastoid lines were developed by EBV immortalization of B lymphocytes obtained both from patients affected with different immunodeficiencies and healthy donors, and established in long-term cultures. Cell lines considered in this study were from patients affected with XLA, namely, P5.00, P6.30, P8.70 (kindly provided by Dr. M.E. Conley, St. Jude Children Hospital, Memphis, TN), and CAR-EBV. All lines were CD38 ${ }^{+}$. Control immunodeficient lines included severe combined immunodeficiency, common variable immunodeficiency, and Wiskott-Aldrich syndrome. DNS-EBV was obtained from a female patient affected with an agammaglobulinemic syndrome reported previously in other patients as phenotypically identical to XLA $(18,19)$. Controls included 15 different cell lines obtained from normal $\mathrm{B}$ cells with the same procedure (20): out of these, CTR-EBV and LG2 were CD38 ${ }^{+}$, while LG14 was $\mathrm{CD} 38^{-}$. All culture supernatants, as well as media from metabolic radiolabeling, were centrifuged and passed through a $0.2 \mu \mathrm{m}$ syringe filter before undergoing other procedures, to rule out the presence of dead cells or derived debris. Spent medium from cultures of multiple myeloma cells, known to release large amounts of soluble CD38 (p39) (8), was also used as positive control.

Antibodies. mAbs used included affinity-purified IB4 (21), IB6 (22), OKT10 (all anti-CD38), O1.65 (anti-HLA class I heavy chain) (23), and CBT8 (anti-CD8) (24). Anti-CD39 was from Serotec (Oxford, UK), while anti-human IgM antiserum was from Organon Teknika/Cappel (Durham, NC). Phycoerythrin (PE)-conjugated Leu-17 (anti-CD38) was from Becton Dickinson (Milan, Italy). FITC- and PE-labeled A1 (anti-CD39) were kindly provided by Dr. G. Aversa (DNAX, Palo Alto, CA).

Flow cytometry analysis. Cells were incubated with the primary antibody for $20 \mathrm{~min}$ at $4^{\circ} \mathrm{C}$. After washing, an FITC-conjugated antimouse Ig was added for $20 \mathrm{~min}$. Cells were then washed again and analyzed on a FACSort ${ }^{\circledR}$ (Becton Dickinson) using Lysis II software.

Modulation experiments and shedding, and endocytosis assays with ${ }^{125}$ I-labeled IB4 ( ${ }^{125}$ I-IB4). Cells for modulation experiments were cultured for $48 \mathrm{~h}$ in the presence of either IB4 mAb or isotypematched CBT8 mAb, washed twice, and analyzed by direct immunofluorescence and flow cytometry analysis. Residual mAb bound to the cell surface was monitored by incubation with FITC-conjugated goat anti-mouse Ig.

${ }^{125}$ I-IB4 was used in acid elution assays, as described previously (25). Briefly, cells were resuspended in RPMI 1640 with $0.2 \%$ BSA and $10 \mathrm{mM}$ Hepes ( $\mathrm{pH} 7.4$ ), and incubated with ${ }^{125} \mathrm{I}$-IB4 for $30 \mathrm{~min}$ on ice, followed by the addition of anti-mouse $\operatorname{IgG} \mathrm{mAb}$. Cells were washed twice and incubated for $4 \mathrm{~h}$ at $37^{\circ} \mathrm{C}$. Supernatants were then collected and counts per minute measured with a Cobra II $\gamma$-counter (Packard, Meriden, CT). After two washings, cells were either incubated in RPMI 1640 medium containing $10 \mathrm{mM}$ Hepes (pH 7.4) or RPMI 1640 buffered to $\mathrm{pH} 2.0$ with $20 \mathrm{mM}$ glycine- $\mathrm{HCl}$ for $5 \mathrm{~min}$, washed again, and counted in a $\gamma$-counter. The proportions of internalized and shed ${ }^{125} \mathrm{I}$-IB4 were determined as the ratio between acid resistant ( $\mathrm{pH} 2.0)$ and supernatant, respectively, and total counts $(\mathrm{pH}$ 7.4 plus shed fraction). Each sample was assayed in triplicate.

Binding inhibition experiments. IB4 $\mathrm{mAb}$ was iodinated as described previously (26). Spent media from XLA, multiple myeloma, or control cell cultures were preincubated overnight with the radiolabeled $\mathrm{mAb}$. $\mathrm{CD} 38^{+}$cells were then added for $2 \mathrm{~h}$, washed twice, and counts per minute of bound mAb counted.
Immunoprecipitation and electrophoretic analysis. Cells $(\sim 2 \times$ $10^{7}$ ) were washed in PBS, preincubated in methionine/cysteine-free medium for $20 \mathrm{~min}$, and then pulsed for $4 \mathrm{~h}$ with $50 \mu \mathrm{Ci} / \mathrm{ml}$ of $\left[{ }^{35} \mathrm{~S}\right] \mathrm{me}-$ thionine $/\left[{ }^{35} \mathrm{~S}\right]$ cysteine (specific activity $1,174 \mathrm{Ci} / \mathrm{mmol}$ ) (ICN, Irvine, CA). For subsequent immunoprecipitation, cells were washed with ice-cold PBS and lysed in PBS containing 3\% 3-[(3-cholamidopropyl)dimethylammonio]-1-propanesulfonate (CHAPS) and 1mM PMSF, as described previously (10). Labeling media were filtered and then immunoprecipitated; supernatants from unlabeled cells were concentrated (to approximately one-fourth of the initial volume) using Centricon filters (Amicon, Beverly, MA). Samples were successively precleared by means of an irrelevant $\mathrm{mAb}$ covalently conjugated to Sepharose CL-4B (Pharmacia, Uppsala, Sweden). Anti-CD38 mAb (IB4, IB6, or OKT10) was then added $(15 \mu \mathrm{g})$, followed by the addition of a rabbit anti-mouse Ig mAb. Immunocomplexes were then recovered with protein G-Sepharose (Pharmacia) for $3 \mathrm{~h}$ at $4^{\circ} \mathrm{C}$, washed twice, and extracted by boiling in SDS sample buffer. Proteins were analyzed on a $10 \%$ SDS-PAGE, and the gels were either silverstained using Quick-silver (Amersham Italia, Milan, Italy) or exposed for autoradiography. Sequential immunoprecipitation experiments were performed by substituting the irrelevant $\mathrm{mAb}$ in the preclearing step with either anti-CD39 mAb or anti-human IgM antiserum.

Western blot analysis. Partially purified p39, p78, and purified gp120 (Chiron, Emeryville, CA) were separated by electrophoresis and transferred onto nitrocellulose. After overnight blocking with $5 \%$ low-fat dried milk in $0.1 \%$ Tris-buffered saline Tween, the membrane was probed with IB4 $\mathrm{mAb}$ and the reaction detected using a horseradish peroxidase-conjugated anti-mouse Ig $\mathrm{mAb}$ and ECL reagents (Amersham).

p78 purification. The protein was quantitatively immunoprecipitated from culture supernatants as described above, and run on an $8 \%$ SDS-PAGE. The gel was stained with $0.25 \mathrm{M} \mathrm{KCl}$ in $1 \mathrm{mM}$ DTT (27), and the bands of interest were excised and eluted in PBS, with sequential incubations at $4^{\circ} \mathrm{C}$ and $37^{\circ} \mathrm{C}$. As controls, membrane CD38 was purified from U937 cells and p39 from a peritoneal ascites obtained from a patient with multiple myeloma (8). Purified gp120 was added as a negative, soluble control.

Comparative peptide mapping by limited proteolysis. Membrane CD38- and p78-purified proteins were ${ }^{125}$ I-labeled with the chloramine $\mathrm{T}$ method (26) and free ${ }^{125} \mathrm{I}$ was eliminated by dialysis against PBS: the specific activity achieved was $\sim 10^{5} \mathrm{cpm} / \mu \mathrm{g}$. Approximately $200,000 \mathrm{cpm}$ of each protein was boiled in SDS sample buffer and loaded on a $15 \%$ SDS-PAGE. Staphylococcus aureus V8 protease (Sigma Italia, Milano, Italy) was prepared in a buffer consisting of $125 \mathrm{mM}$ Tris (pH 6.8), $1 \mathrm{mM}$ EDTA, $2.5 \mathrm{mM}$ DTT, and $0.1 \%$ SDS at a final concentration of $0.5 \mu \mathrm{g} / \mathrm{ml}$ and directly overlaid on samples in the gel wells (28). When the dye line had migrated half the distance in the stacking gel, the power was disconnected and digestion was allowed to proceed for $5 \mathrm{~min}$. The run was then completed and the gel soaked in $1 \mathrm{M}$ salicylic acid for $30 \mathrm{~min}$, dried, and exposed for fluorography.

Determination of cyclase and hydrolase activity. p78 and p39 proteins were immunoprecipitated from supernatants (see above), concentrated previously using a 50-kD cut-off for XLA samples, and a 30-kD cut-off for the myeloma sample: thus, possible activity due to undetectable amounts of p39 in XLA culture media was excluded by ultrafiltration. As negative controls, culture media from multiple myeloma cells were concentrated with a 50-kD cut-off membrane before immunoprecipitation. Both the conventional and the high-molecular weight forms of CD38 (p45 and p190, respectively) were partially purified from DNS-EBV lysates. Immune complexes were gently eluted with $100 \mathrm{mM}$ glycine- $\mathrm{HCl}(\mathrm{pH} 2.8)$ and immediately neutralized with $1 \mathrm{M}$ Tris. Approximate amounts of the partially purified protein were estimated by running parallel samples on SDS-PAGE. After silver staining, the bands of interest were scanned and compared to known amounts of protein standards. Cyclase and cADPR hydrolase activities of either immunoprecipitated proteins or total concentrated supernatants were assayed at $37^{\circ} \mathrm{C}$ in the presence of $10 \mathrm{mM}$ Tris- $\mathrm{HCl}$ 
( $\mathrm{pH}$ 7.4) and $0.2 \mathrm{mM}$ nicotinamide guanine dinucleotide $\left(\mathrm{NGD}^{+}\right)$or $0.1 \mathrm{mM}$ cADPR, respectively, in a total volume of $200 \mu \mathrm{l}$. At various times $(15,30$, and $60 \mathrm{~min}), 50 \mu \mathrm{l}$-aliquots were withdrawn, deproteinized with TCA, briefly centrifuged, and the TCA was removed from the supernatants with diethyl ether. The samples were then subjected to reverse phase HPLC as described previously (29). Cyclase activity was also determined on whole cells. The incubation was done for $1 \mathrm{~h}$ at $37^{\circ} \mathrm{C}$ in the presence of $100 \mu \mathrm{M} \mathrm{NGD}{ }^{+}(30)$. The reaction was stopped by adding $5 \%$ SDS and fluorescence intensity measured with a spectrophotometer at $310 \mathrm{~nm}$ excitation and $400 \mathrm{~nm}$ emission.

\section{Results}

Membrane CD38 expression. Immunodeficient B cell lines did not display significant differences in CD38 expression when compared to EBV lines derived from healthy individuals, even though CD38 levels were higher in some of them (e.g., P5.00 and P8.70) than in their normal counterparts (Fig. 1 $A$ ). CD21, which is the EBV and CRII receptor, was included as control because of its proven lateral association with CD38 on B cells (31), and it demonstrated comparable levels of expression (data not shown). CD38 levels were also comparable in terms of surface cyclase activity (Fig. $1 B$ ).

CD38 shedding and internalization. Modulation of the CD38 molecule from the membrane was initially studied by
FACScan ${ }^{\circledR}$ analysis (Fig. $2 A$ ). The binding of IB4 mAb to CD38 expressed on $\mathrm{B}$ cell membranes induced a consistent downmodulation of the molecule, quantitatively comparable in immunodeficient and normal B cells. The observed effects cannot be secondary to epitopic competition between IB4 and PE-conjugated Leu17, since very low levels of surface IB4 $\mathrm{mAb}$ were detectable after $48 \mathrm{~h}$, as highlighted by staining with an FITC-labeled goat anti-mouse Ig (data not shown).

Shedding and internalization ratios of bound ${ }^{125} \mathrm{I}-\mathrm{IB} 4$ were further studied by acid elution assay (Fig. $2 \mathrm{~B}$ ). This procedure allows the removal of $\sim 95 \%$ of membrane-bound radioactivity, without significantly affecting cell viability or the percentage of internalized ${ }^{125}$ I-labeled mAbs (32). The differences in endocytosed fractions between immunodeficient and control cell lines proved negligible. On the contrary, shedding was more prominent in cell lines derived from patients. In conclusion, internalization and shedding processes occur both in normal or pathological B cells, while shedding rates are increased in XLA and related conditions. Moreover, these events can be triggered by CD38 ligation by specific mAbs, likely mimicking the interactions occurring with the natural ligand(s) (32).

Binding inhibition and supernatant cyclase activity. The test selected relied upon the ability of different culture media to inhibit ${ }^{125} \mathrm{I}-\mathrm{IB} 4 \mathrm{mAb}$ binding to $\mathrm{CD} 38^{+}$cells (Fig. $3 \mathrm{~A}$ ). The
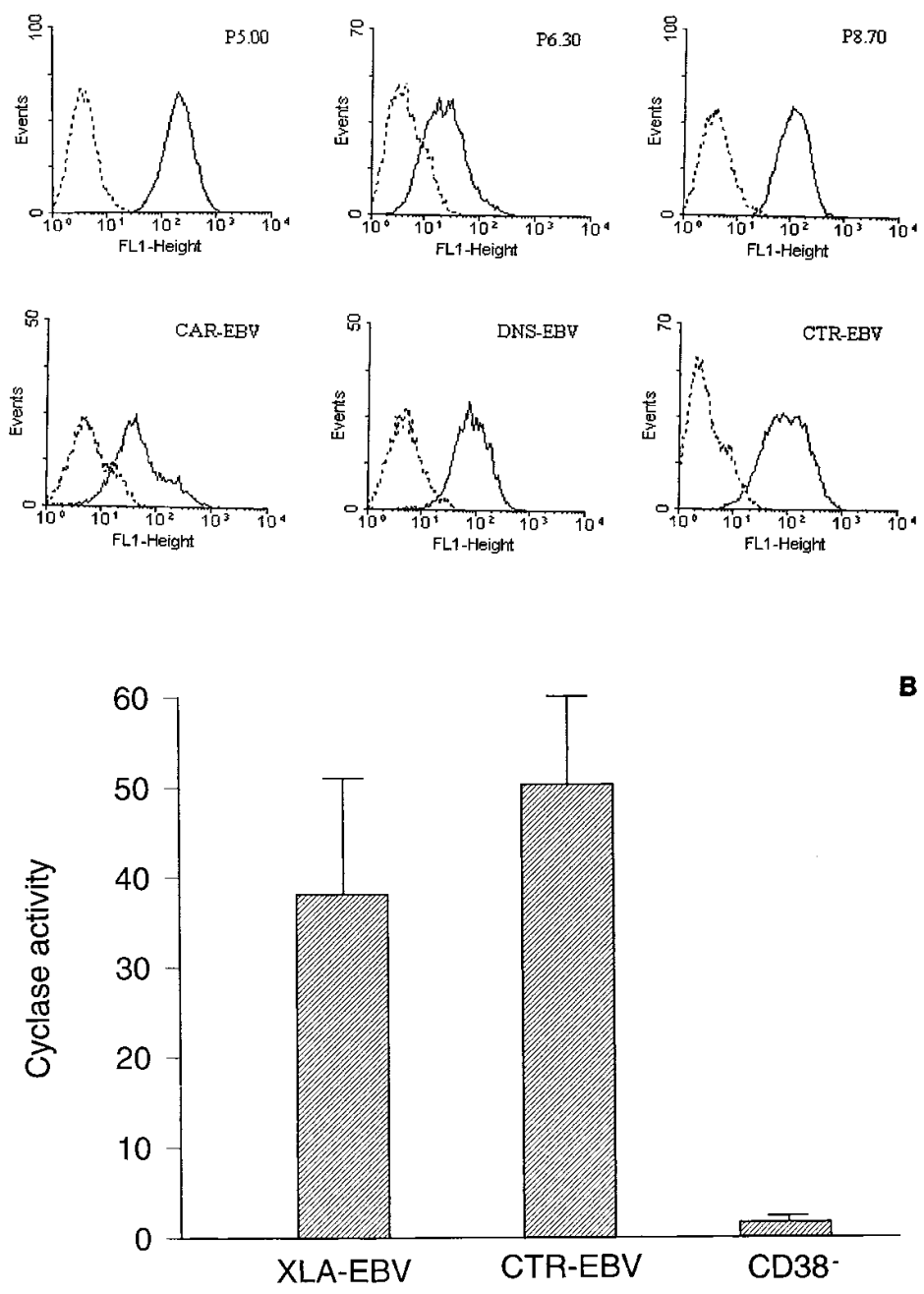

Figure 1. Comparison of membrane CD38 expression and enzymatic activity between XLA and control EBV lines. $(A)$ One-parameter flow cytometric $\left(\right.$ FACScan $\left.^{\circledR}\right)$ analysis of CD38 expression on immunodeficient and control lines. Cells were stained with an FITC-conjugated anti-mouse Ig after incubation with IB4 mAb (dashed lines) or isotypematched control (solid lines). $x$ axis $=$ fluorescence intensity/ cells; $y$ axis $=$ number of cells registered/channel. Number of cells tested $=10,000$. (B) ADP-ribosyl cyclase activity detected on whole cells, using $\mathrm{NGD}^{+}$as a substrate. Enzyme activity is expressed as absorbance at $410 \mathrm{~nm}$ emission and $300 \mathrm{~nm}$ excitation. Results refer to a representative experiment performed in duplicate with different XLA-EBV cell lines. 

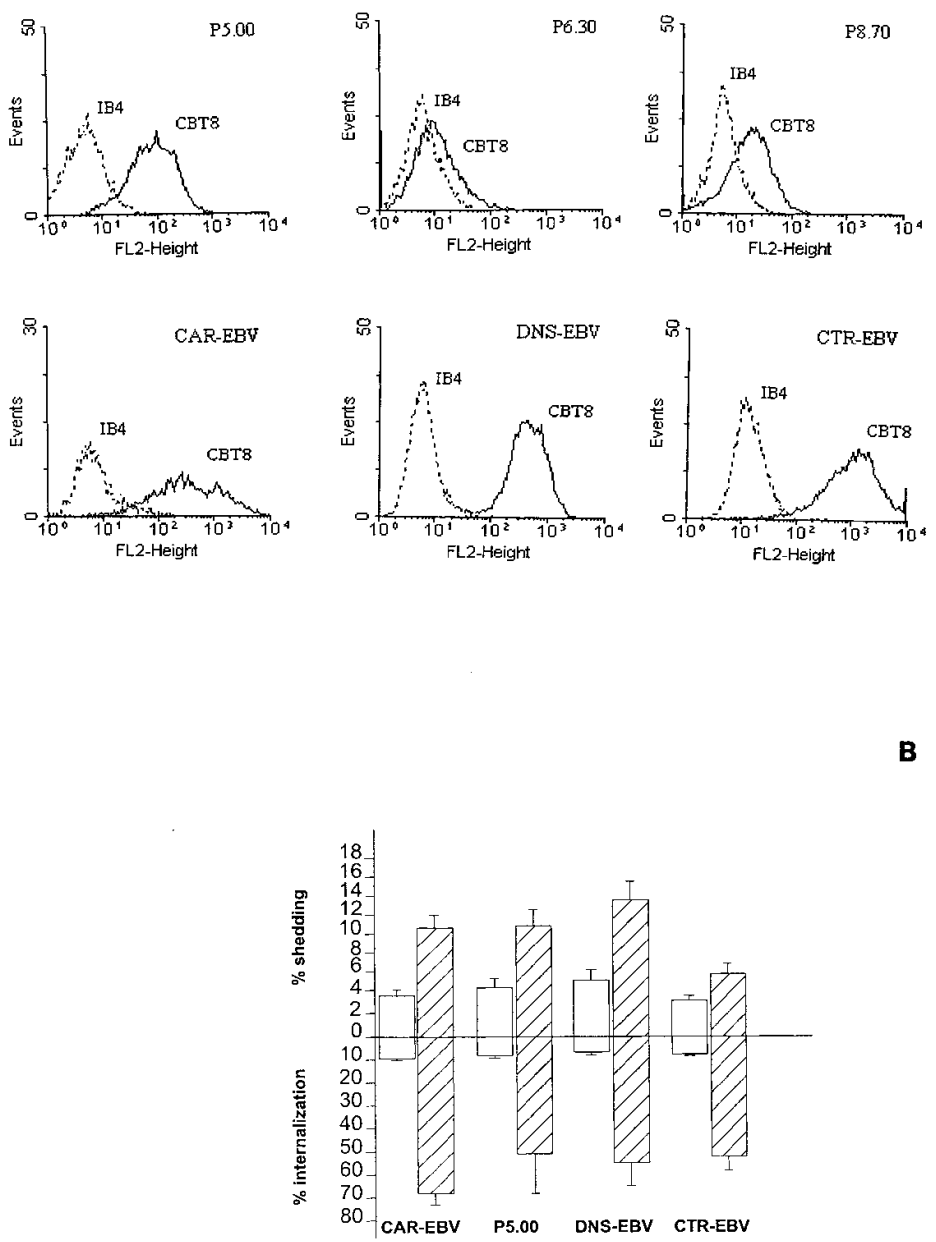

Figure 2. IB $4 \mathrm{mAb}$ endocytosis and shedding. $(A) \mathrm{CD} 38$ downmodulation after a 48 -h culture in the presence of either IB4 or irrelevant idiotype-matched CBT8 mAb, as highlighted by PE-conjugated Leu-17. $x$ axis $=$ fluorescence intensity/cells; $y$ axis $=$ number of cells registered/channel. Number of cells tested $=5,000$. (B) Internalized and shed fractions of ${ }^{125} \mathrm{I}$-IB4 $\mathrm{mAb}$ were compared between different cell lines, either at $0 \mathrm{~h}$ (white bars) or $4 \mathrm{~h}$ (hatched bars). The graphic shows the ratios of acid-resistant or supernatant counts to the total cell and supernatant-associated label (as described in Methods). Results refer to a representative experiment performed in triplicate.

presence of supernatants ( $2 \mathrm{~d}$-culture, range $200-400 \mu \mathrm{l}$ ) from XLA-EBV cells reduced the binding of ${ }^{125} \mathrm{I}-\mathrm{IB} 4 \mathrm{mAbs}$ to the cell surface by $\sim 50 \%$, as compared to controls; moreover, the effect was dose-dependent. The observation that p78-rich supernatants inhibit ${ }^{125} \mathrm{I}-\mathrm{IB} 4 \mathrm{mAb}$ binding more efficiently than those containing p39 (e.g., myeloma culture media) is in line with the possibility that p78 might contain twice the amount of epitopes available for $\mathrm{mAb}$ ligation. Further, cyclase activity was determined on different concentrated supernatants (Fig. 3 $B$ ), showing a clear correlation between the degree of enzymatic activity and the ability to inhibit ${ }^{125} \mathrm{I}-\mathrm{IB} 4 \mathrm{mAb}$ binding.

Identification of the soluble molecule. Immunoprecipitation experiments performed with IB4 mAb on culture supernatants from metabolically labeled XLA cells showed a 78-kD band, both under reducing and nonreducing conditions (Fig. $4 A$, lane 2; nonreducing not shown). Thus, the 78-kD soluble form is, indeed, a product of cellular synthesis, being obtained after internal radiolabeling. Additionally, IB4 mAb immunoprecipitated both the 45- and 190-kD high-molecular mass form of CD38 from the cell membrane fraction, both in XLA (Fig. $4 A$, lane 1 ) and control B-EBV cell lysates (Fig. $4 A$, lane 3 ), as well as in other related B cell immunodeficiency samples (e.g., DNS-EBV). The main difference was that the culture medium obtained after metabolic labeling of the EBV lines from healthy individuals and control immunodeficiencies did not yield any detectable amount of the soluble p78 molecule (Fig. $4 A$, lane 4). Immunoprecipitation from LG14 cells (CD38 $\left.{ }^{-}\right)$ did not show any band either from the membrane fraction or the labeling supernatant (data not shown). The 78-kD band was also observed by immunoprecipitating culture media of unlabeled XLA cells with three different anti-CD38 mAbs, namely IB4, IB6, and OKT10 (Fig. 4 B, lanes 1-3). Cross-specificity was excluded by using the isotype-matched irrelevant O1.65 mAb (anti-HLA class I heavy chain) (Fig. 4 B, lane 4). Cross-reactivity with bovine components of the medium was ruled out by treating normal culture media with IB4 mAb under the same conditions (Fig. 4 B, lane 5).

Anti-CD38 mAbs recognized the partially purified p78 in Western blots (Fig. $4 C$, lane 1 ). A reaction was also observed with partially purified p39 (Fig. $4 C$, lane 2), while no signals were reported using either IB4 $\mathrm{mAb}$ on an irrelevant protein (Fig. $4 C$, lane 3 ) or the isotype-matched $01.65 \mathrm{mAb}$ on partially purified p78 (Fig. $4 \mathrm{C}$, lane 4 ). This finding indicates that IB4 $\mathrm{mAb}$ recognizes a linear epitope on $\mathrm{p} 78$, as is the case for CD38, offering further proof that the two molecules display a similar immunoreactivity (33).

CD39 and surface IgM were further investigated as sources of possible pitfalls to the correct interpretation of the results by unexpected cross-reactions with CD38 mAbs. CD39 is a $78-\mathrm{kD}$ surface protein and a marker of EBV-transformed cell 

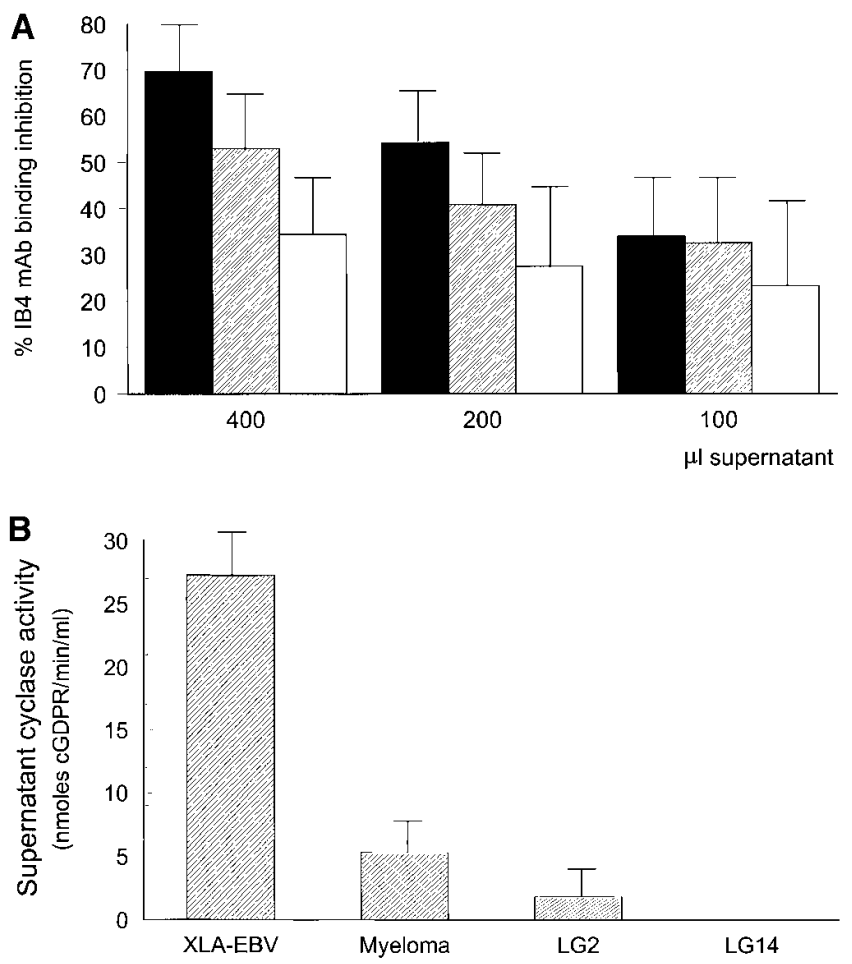

Figure 3. Inhibition of ${ }^{125} \mathrm{I}-\mathrm{IB} 4 \mathrm{mAb}$ binding to target cells and cGDPR production by supernatants of XLA, myeloma, and control cultures. (A) Increasing volumes of XLA supernatant (black bars), myeloma supernatant (hatched bars), and control supernatant (white bars) were preincubated with ${ }^{125} \mathrm{I}$-IB4 $\mathrm{mAbs}$ and subsequently added to U937 cells. The percent binding inhibition was calculated after background subtraction. Results refer to a representative experiment performed in triplicate. $(B)$ The same supernatants were assayed for cyclase activity after concentration. Results refer to a representative experiment performed in duplicate.

lines highly expressed by all the EBV lines studied (34), which displays lateral association with CD38 (35). No soluble forms are reported for this molecule. Other instances include functional complementarities with $\mathrm{CD} 38$, as is the case for PC-1 (36). Lack of cross-reactivity was established by the dissociation in terms of expression between CD39 (expressed by all the EBV lines) and CD38 (whose expression is only present in the majority of EBV lines). Indeed, LG2, a CD $38^{+} \mathrm{EBV}$ line used as a model for the study of CD39 (37), did not generate any p78 band in immunoprecipitation experiments. Further, sequential immunoprecipitation ruled out any epitopic similarity between CD38 and CD39 (Fig. $5 \mathrm{~A}$, lanes 1 and 2).

Mistaking $\mathrm{p} 78$ for an IgM heavy chain was also ruled out by sequential immunoprecipitation (Fig. $5 A$, lanes 3 and 4). Further evidence of the differences between p78 and IgM heavy chains came from XLA lines virtually negative for surface IgM (e.g., CAR-EBV) (Fig. 5 B), whose culture supernatants yielded significant amounts of an immunoprecipitable $78-\mathrm{kD}$ band (Fig. 5 C). Moreover, IB4 mAb immunoprecipitation from metabolically radiolabeled peripheral blood lymphocytes obtained from a patient with Waldenstrom macroglobulinemia (with $78 \% \mathrm{CD} 19^{+}$lymphocytes and producing high amounts of IgM) did not show any soluble form released in the medium; however, both p190 and p45 were precipitated from the membrane fraction (data not shown). Similar results were obtained from multiple myeloma cell lines (e.g., U266 and SK-MM1) as well as from pre-B leukemia lines (e.g., Nalm-6 [38] and BV173 [39]), and from preparations of lymphocytes obtained from umbilical cord vein.

Comparative peptide mapping between membrane CD38 and $p 78$. The results of peptide mapping of p78 and CD38 with the serine protease $S$. aureus V8 indicate that the two proteins share several peptides (Fig. 6, 1-4). Furthermore, the digestion of both molecules results in a $39-\mathrm{kD}$ band. This result reconfirms data reported by Funaro et al. (8), who demonstrated a partial blockage of $\mathrm{p} 39$ production from membrane $\mathrm{CD} 38$ by the serine protease inhibitor $N$ - $\alpha$-p-tosyl-L-lysine chloromethyl ketone. As a $39-\mathrm{kD}$ band is also observed after p78 digestion by $S$. aureus V8, a reasonable inference is that the two molecules may undergo similar cleavage processes. Peptides 1 and 3 (Fig. 6) migrate with apparent masses of 30 and $22 \mathrm{kD}$, respectively, as observed earlier by Alessio et al. (40). Moreover, Funaro et al. reported that p39 coprecipitates with a soluble $30-\mathrm{kD}$ form (8), probably a major degradation product; this is a further, indirect evidence that serine proteases are involved in the production of soluble forms, the digestion with $S$. aureus $\mathrm{V} 8$ giving a prominent $30-\mathrm{kD}$ band.

Determination of cyclase and hydrolase activities. The p78 protein was characterized in terms of catalytic activities. Cyclase activity was measured by using $\mathrm{NGD}^{+}$, an $\mathrm{NAD}^{+}$analogue that is converted to the corresponding cyclic product cyclic guanine diphosphate ribose (cGDPR), which in turn is
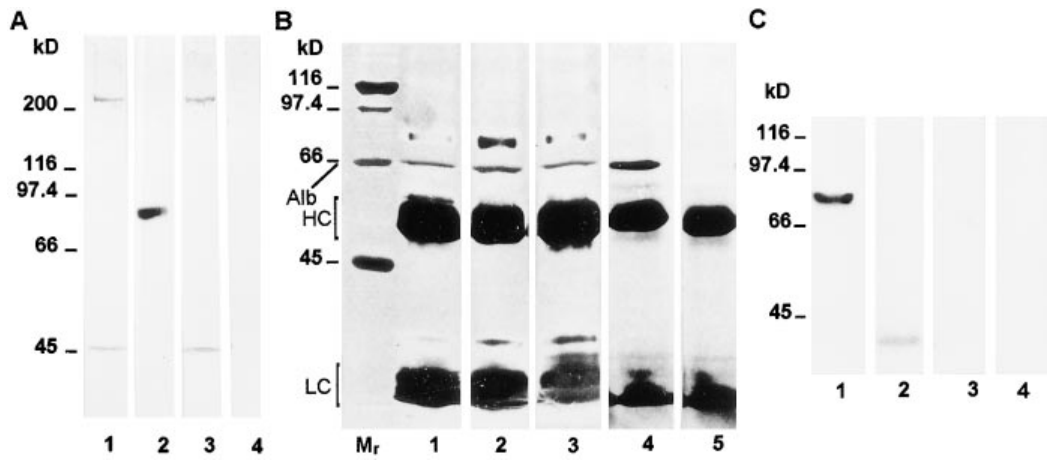

Figure 4. Immunoprecipitation from supernatants and lysates of immunodeficient $B$ cells with antiCD38 mAbs and Western blot analysis. (A) CD38 immunoprecipitated with IB4 mAbs from metabolically labeled XLA and LG2 cells, respectively (lanes 1 and $3)$; immunoprecipitate with IB4 $\mathrm{mAb}$ from XLA and LG2 supernatants, respectively (lanes 2 and 4 ). (B) Immunoprecipitation from unlabeled XLA spent media either with different anti-CD38 mAbs, IB4, IB6, and OKT10 (lanes 1-3, respectively) or an irrelevant $\mathrm{mAb}$ (lane 4); immunoprecipitation with IB4 $\mathrm{mAb}$ from unspent culture medium (lane 5). HC and LC extrabands correspond to the heavy and light chains of the IgG used for immunoprecipitation, and Alb to the albumin present in all the culture media tested. $(C)$ Partially purified p78 immunoreactivity with IB4 mAb in Western blot (lane 1), compared to p39 (lane 2), gp120 (lane 3), and p78 probed with the isotype-matched $01.65 \mathrm{mAb}$ (lane 4). 

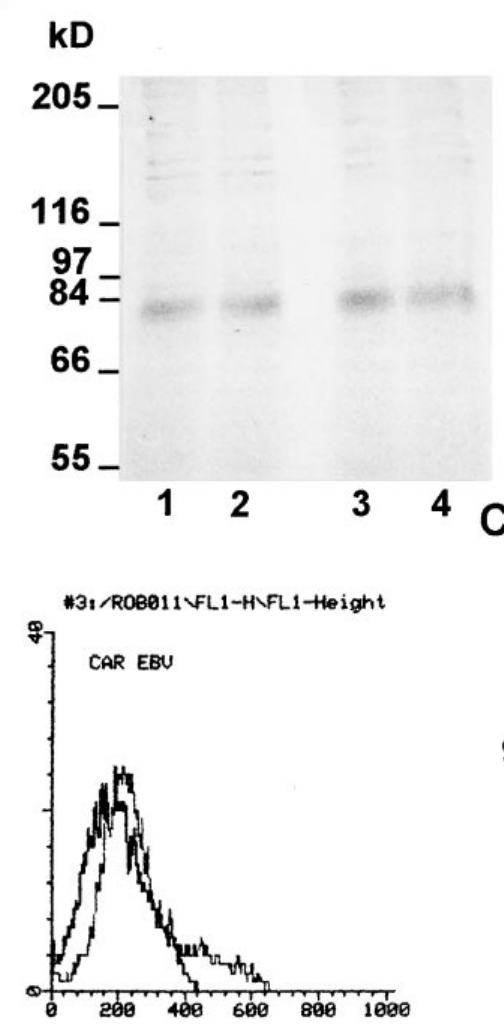

$\mathrm{kD}$

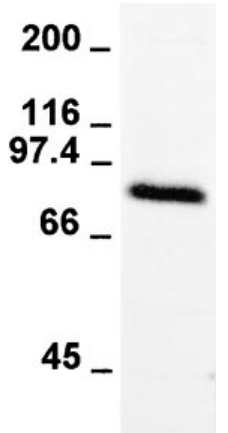

Figure 5. Sequential immunoprecipitation with anti-human IgM antiserum and IB4 mAb. (A) Sequential immunoprecipitation experiments were performed by using an irrelevant $\mathrm{mAb}$ (lanes 1-3), antihuman IgM antiserum (lane 4), or anti-CD39 mAb (lane 2) in the preclearing step before incubation with IB4 $\mathrm{mAb}$. (B) XLA lines with low-to-nil expression of surface IgM are positive, as well, for p78 release in the supernatant $(C) x$ axis $=$ fluorescence intensity/cells; $y$ axis $=$ number of cells registered/channel. Number of cells tested $=$ 10,000 .

much more resistant to hydrolysis than cADPR. This feature allows a more precise quantitative assay, since cyclase scores are not influenced by the correlated cADPR hydrolase activity (30). In addition, this substrate is much more specific for CD38, since it is not degraded by possible contaminating NADase activities, which instead convert $\mathrm{NAD}^{+}$directly to

Figure 6. Comparative peptide mapping by $S$. aureus V8 limited proteolysis between p78 and $45-\mathrm{kD}$ membrane CD38. p78 and the conventional $45-\mathrm{kD}$ form of membrane CD38 (p45) were compared for common peptides after limited proteolysis using S. aureus V8 protease. Double solid pointers point to residual undigested proteins, whereas single solid pointers point to common peptides. The indicator points to a unique, unshared peptide generated from p78 digestion.

\begin{abstract}
ADPR $(30,41)$. Results obtained after testing the $78-\mathrm{kD}$ form are summarized in Table I. The p78 protein from all the lines tested featured significant cyclase and hydrolase activities (Table I, rows 1 and 2, respectively). The specific activities obtained were quite concordant either in the group of the different XLA lines (Table I, rows 3 and 4) or between p78 and p39 (Table II), while the membrane p45 form showed higher scores for both activities. However, the ratio between the two activities is approximately one for both surface and soluble molecules (Table II, row 3), a ratio reported as typical for the CD38 ectoenzyme $(29,41)$. CD38 modification to a $78-\mathrm{kD}$ form does not affect this ratio, which is instead shifted towards a dominant cyclase activity in p190 (Table II), as reported previously (10). A negative control, obtained by concentrating multiple myeloma culture media with a $50-\mathrm{kD}$ cut-off membrane, did not yield detectable enzymatic activities (Table II).
\end{abstract}

\title{
Discussion
}

As for many other receptors of unknown function, the study of diseases has represented a twofold valence: on one side, it is aimed at defining the role of such receptors in the pathogenesis of the disease and, on the other, it provides hints about their functions in physiological conditions. One of the few instances where CD38 is clearly involved is in murine xid, a pathology model where the signal transduction and btk phosphorylation induced by the molecule are defective (15-17). The inference derived from the murine model cannot be entirely transferred to XLA for two reasons. $(A)$ Murine CD38 displays relevant differences in comparison to its human counterpart (42). For

Table I. Comparative Analysis of p78 Enzymatic Activities Between Different XLA Cell Lines

\begin{tabular}{lrrr}
\hline & p78 (P5.00) & p78 (P6.30) & p78 (DNS-EBV) \\
\hline GDP-ribosyl cyclase (nmol cGDPR/min/ml) & $0.524 \pm 0.131$ & $0.345 \pm 0.017$ & $0.855 \pm 0.410$ \\
cADPR hydrolase (nmol ADPR/min/ml) & $0.699 \pm 0.125$ & $0.511 \pm 0.056$ & $0.834 \pm 0.187$ \\
Cyclase specific activity (nmol/min/mg) & $17.449 \pm 4.405$ & $13.760 \pm 0.712$ & $24.360 \pm 11.651$ \\
Hydrolase specific activity (nmol/min/mg) & $23.285 \pm 4.207$ & $20.405 \pm 2.215$ & $23.771 \pm 5.295$ \\
Cyclase/Hydrolase ratio & $0.740 \pm 0.055$ & $0.687 \pm 0.109$ & $0.964 \pm 0.275$ \\
\hline
\end{tabular}

p78, partially purified from different immunodeficient B lines, was tested for both cyclase and hydrolase activities. Values are expressed as the mean $\pm \mathrm{SD}$ of three different experiments. 


\begin{tabular}{|c|c|c|c|c|c|}
\hline & p78 & p39 & $\mathrm{p} 45$ & p190 & $\begin{array}{l}\text { Myeloma } \\
\text { 50-kD cut-off }\end{array}$ \\
\hline Cyclase specific activity (nmol/min/mg) & $18.523 \pm 4.393$ & $17.025 \pm 0.923$ & $89.591 \pm 7.696$ & $133.917 \pm 9.568$ & 0 \\
\hline Hydrolase specific activity ( $\mathrm{nmol} / \mathrm{min} / \mathrm{mg}$ ) & $22.487 \pm 1.485$ & $30.187 \pm 7.512$ & $103.695 \pm 12.832$ & $50.117 \pm 6.095$ & 0 \\
\hline Cyclase/Hydrolase ratio & $0.797 \pm 0.120$ & $0.597 \pm 0.121$ & $0.864 \pm 0.181$ & $2.672 \pm 0.515$ & $0 / 0$ \\
\hline
\end{tabular}

Partially purified molecules were assayed for both cyclase and hydrolase activities. Scores reported for p78 are expressed as the mean of the values reported in Table I; the other scores are expressed as the mean \pm SD of three different experiments. The last column shows a negative control obtained by concentrating myeloma culture supernatant with a 50-kD cut-off membrane, thus eliminating the p39 fraction.

instance, murine CD38 pattern of expression throughout B cell differentiation from follicular B cells $\left(\mathrm{CD} 38^{+}\right)$to germinal center $\mathrm{B}$ cells $\left(\mathrm{CD}^{38 \mathrm{dim} /-}\right)$ and plasma cells $\left(\mathrm{CD} 38^{-}\right)$is exactly opposite to that reported for the human model (43). (B) In spite of sharing the same molecular defect, xid shows, at least in the majority of mouse strains, normal levels of peripheral B cells (although phenotypically immature) and Igs of all isotypes (with only reduced levels of $\mathrm{IgM}$ and $\mathrm{IgG}_{3}$ ) (44). On the contrary, XLA displays extremely low levels of both Ig (45) and B cells (46). To circumvent the drawback, we used EBV-immortalized cells derived from such patients.

Our initial analysis of CD38 in selected immunodeficiencies was restricted to some structural aspects. The comparative analysis with EBV lines obtained from healthy donors did not highlight relevant differences in the membrane density of CD38. Further, the molecule maintains enzymatic activities almost overlapping with that of normal counterparts, and the ability to be downmodulated upon ligation of agonistic mAbs via internalization is also maintained, even if the modulation is reported to be reduced or absent in xid B cells (15). The novelty of this study is the identification of a protein released from XLA cells. The characteristics of the protein are the $M_{\mathrm{r}}$ of 78,000 and catalytic properties strikingly similar to that featured by membrane CD38. Further, XLA-EBV cells, B cells from other related immunodeficiences, and normal controls, express the high-molecular weight membrane form of CD38 (p190), initially reported only in differentiated HL-60 (10). These observations confirm that the posttranslational process leading to the production of p190 is not confined to selected cell lines or differentiation conditions (Mallone, R., unpublished observations).

Interestingly, the p78 protein was also isolated from lymphocytes immortalized from a female patient affected with agammaglobulinemia. This disease, although reported in other patients to be phenotypically identical to XLA (18), does not show any mutation on the btk gene (19). Moreover, several congenital XLA-like agammaglobulinemias affecting both males and females display an autosomic recessive pattern of inheritance and absence of $b t k$ alterations (47). Mutations in the $\mu$ heavy chain gene have been recently identified as responsible for the majority of these syndromes (48). Thus, p78 release apparently is not specific for the XLA condition, but seems to be a feature of B lymphocytes with severe differentiation defects. Whether the mechanism underlying $\mathrm{p} 78$ release is common to both conditions or rather involves different pathways remains to be determined. Indeed, an association between CD38 and membrane Ig in human B cells has been demonstrated (31): therefore, the altered processing observed in this related condition might also be due to a defective interaction between these two molecules.

Two distinct hypotheses can be formulated to explain $\mathrm{p} 78$ synthesis. The first is that $\mathrm{p} 78$ is produced ab initio as a $78-\mathrm{kD}$ soluble form, either due to alternative mRNA splicing (49) or increased expression of a presently unknown soluble protein belonging to the CD38 family (50). A second hypothesis is that CD38 undergoes oligomerization, a posttranslational process that could take place either within the cell or on the membrane. Such a mechanism has been described in ATRA-induced HL-60 cells (10) and erythrocyte membranes (12). More recently, the crystallographic analysis of Aplysia ADP-ribosyl cyclase (51), a soluble protein that is a phylogenetic ancestor of human CD38 (52), has revealed two forms of crystals, one consisting of a dimer (two molecules) and the other of a double dimer (four molecules). Further, indirect evidence was obtained by production of sCD38 in Pichia pastoris (53) that yielded, besides the expected $30-\mathrm{kD}$ protein, a second species exhibiting a molecular weight of twice the conventional form. Based on this body of data, three different models can be proposed (Fig. 7). In the most simple one $(A)$, two p45 molecules could undergo dimerization and then be proteolytically cleaved, giving rise to $\mathrm{p} 78$. Against this speculation is the fact that no relevant bands of $\sim 78 \mathrm{kD}$ are isolated from XLA membrane fractions. A second model $(B)$ could involve membrane CD38 acting as a docking site for its own soluble $39-\mathrm{kD}$ form and then undergoing cleavage, but no consistent $39-\mathrm{kD}$ band is highlighted from XLA supernatants. Thus, the model best supported by our data is that of CD38 oligomerization, leading to p190 production and subsequent release of p78 molecules in the supernatant $(C)$.

Release of cell surface molecules is a common finding in many disease states. The released molecules may be eliminated or included in a regulatory network, either by competing in cell-cell adhesions or triggering signals in cells expressing the relevant ligands (54). CD38 is known to perform key roles both as an adhesion molecule (3) and as a signaling structure $(2,55)$, with different biological effects. For instance, CD38 signaling prevents apoptosis of human germinal center CD $38^{+}$ B cells (56), while it transduces negative signals on the growth of immature B lymphoid cells in the bone marrow (57). Both functions are probably mediated by binding with one or more ligands (4), one of which is identified as CD31 (5). Evidence that the signaling role of CD38 is mediated by the interaction with its ligand came from a study on the role of these molecules in the activation of MHC nonrestricted T cell cytotoxicity (58). Almost identical observations were made in murine models, where binding of a CD38 homologue by a mAb not only 


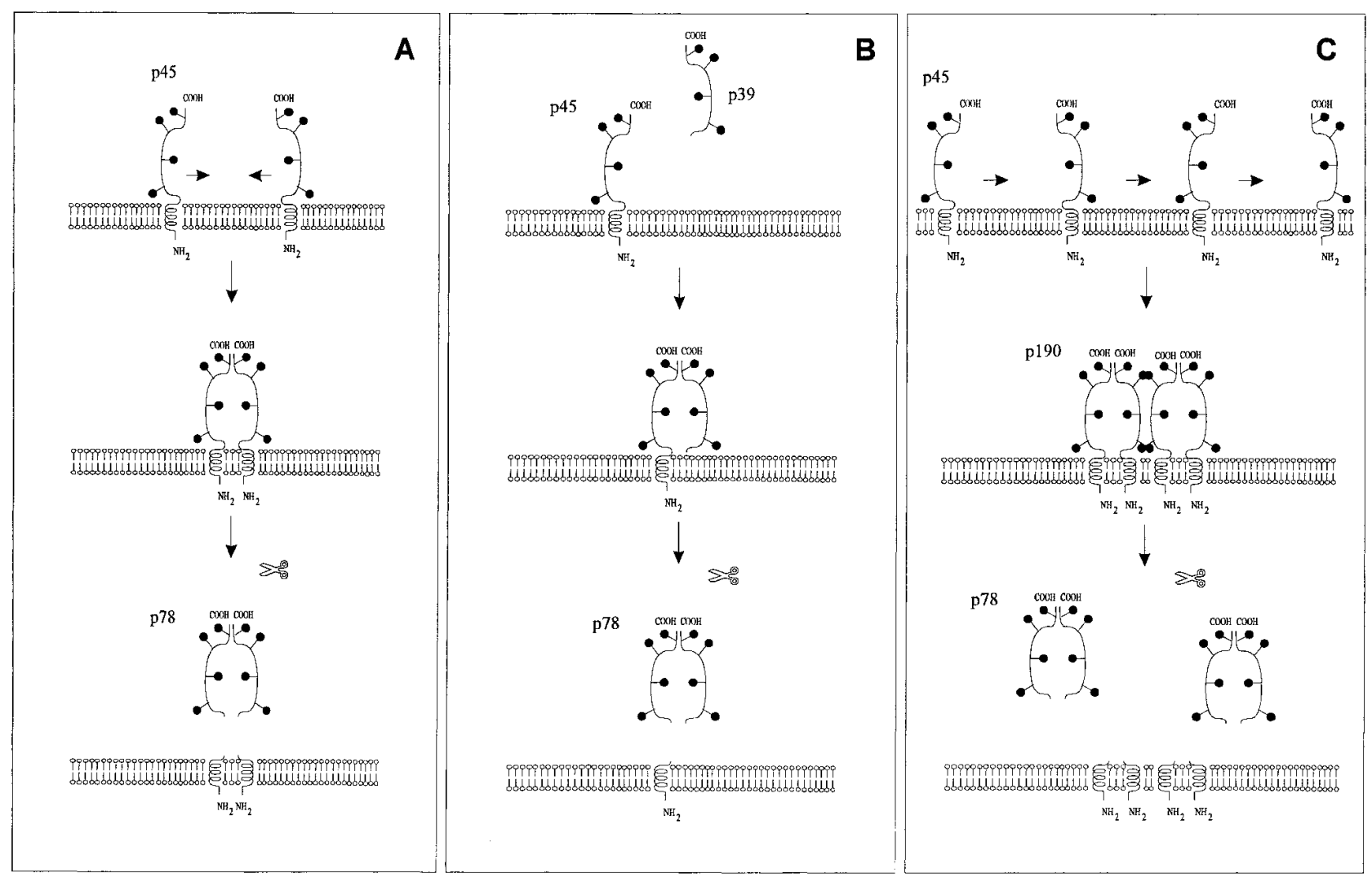

Figure 7. Possible models of CD38 oligomerization and p78 production. $(A) \mathrm{p} 45$ dimerization and subsequent proteolytic cleavage. $(B) \mathrm{p} 45$ acting as a docking site for p39, giving rise to a complex subsequently released in the supernatant. $(C)$ p45 oligomerization and p190 production; the high-molecular weight form could then be cleaved to give p78 molecules.

induces B lymphocytes to proliferate, but also partially prolongs in vitro survival and protects against apoptosis. The same $\mathrm{mAb}$ fails to deliver effective signals to xid B cells (59). These observations raise the possibility that membrane and soluble CD38 forms might compete for binding the ligand(s), with detrimental effects in cell-cell interactions. The resulting impaired cross-talk could inhibit the progression in the B-lineage pathway. p78 could exert this in vivo hypothetical role mainly by operating in discrete microenvironments. Even if circulating or tissue immunodeficient B lymphocytes do release some amounts of $\mathrm{p} 78$, the protein would be highly diluted in the bloodstream, as a result of the very low number of peripheral B cells; nonetheless, the effects secondary to shedding could reach physiological significance (e.g., block of adhesion and signal triggering on cells expressing the ligands) in closed environments, such as lymph nodes or bone marrow. Moreover, the XLA phenotype may be heterogeneous, ranging from a nearly agammaglobulinemic state with complete lack of circulating $\mathrm{B}$ cells to milder conditions with substantial levels of $\mathrm{IgM}$, IgG, and $\operatorname{IgA}$, and/or a low, but detectable number of peripheral blood B cells $(45,46)$. One explanation for this phenotypic heterogeneity lies in the many different types of $b t k$ mutations described so far. Alternatively, some B cell precursors manage to escape the block in the development and are able to undergo further, though incomplete, differentiation and to synthesize Ig. This is in line with the loss of surface CD38 physiologically occurring during progression of B maturation, where the molecule is reexpressed only upon activation in the terminal stages (61).

Whether p78 release is peculiar to XLA and, more generally, immunodeficient $\mathrm{B}$ lymphocytes, or indeed is exacerbated in the model is not answered in full at the moment. Control supernatants tested by immunoprecipitation for the presence of p78 were obtained from (a) EBV lines derived from patients with common variable immunodeficiency, severe combined immunodeficiency, and Wiskott-Aldrich syndrome; $(b)$ continuous human tumor cell lines of $\mathrm{B}$, multiple myeloma, $\mathrm{T}$ and monocytic origin; and $(c)$ cultured PBMC from healthy donors and patients with myeloma and Waldenstrom's macroglobulinemia. In all instances, the p78 protein was undetectable, at least in these analytical assays. Similarly, EBV lines from healthy donors did not display any relevant 78-kD band immunoprecipitated from the supernatant, even if minimal enzymatic activities were detected and acid elution assays highlighted some degree of IB4 $\mathrm{mAb}$ shedding. A second possibility is that $\mathrm{p} 78$ release might be peculiar to some stage of differentiation, i.e., the pre-B stage, rather than the immunodeficiency condition. However, immunoprecipitation experiments performed on pre-B leukemia cell lines as well as lymphocytes obtained from umbilical cord veins, known to contain a large percentage of immature B cells, did not show any 78-kD protein in the supernatant, although the membrane fractions were positive for both $\mathrm{p} 45$ and $\mathrm{p} 190$. A third possibility could be that immunodeficient B cells were, in some way preselected 
by the EBV immortalization so that the continuous cell lines obtained would represent only a discrete B subset. This cannot be ruled out, given the observation that the EBV receptor CD21 is found on a lower percentage of XLA B cells compared to normal B cells (46), this molecule being expressed later in ontogeny. Many of these questions will be answered by the imminent availability of a sensitive assay for the detection of soluble CD38 circulating in the biological fluids.

\section{Acknowledgments}

This work was supported by grants E662 (F. Malavasi) and E668 (L.D. Notarangelo) from Telethon (Rome, Italy), by the Istituto Superiore di Sanità ("AIDS" and "Tuberculosis" Projects, Rome, Italy), by the Associazione Italiana Ricerca Cancro (AIRC, Milan, Italy), by the Special Project "Biotechnology" (Consiglio Nazionale delle Ricerche, CNR) and by research grants from the CRT and CARIVERONA Foundations. K. Mehta is the recipient of grants from the Texas Higher Education Coordinating Board (ATP-15-012) and the U.S. Food and Drug Administration (FDR-000923).

\section{References}

1. Malavasi, F., A. Funaro, S. Roggero, A. Horenstein, L. Calosso, and K. Mehta. 1994. Human CD38: a glycoprotein in search of a function. Immunol. Today. 15:95-97.

2. Funaro, A., G.C. Spagnoli, C.M. Ausiello, M. Alessio, S. Roggero, D. Delia, M. Zaccolo, and F. Malavasi. 1990. Involvement of the multilineage CD38 molecule in a unique pathway of cell activation and proliferation. J. Immunol. 145:2390-2396.

3. Dianzani, U., A. Funaro, D. DiFranco, G. Garbarino, M. Bragardo, V. Redoglia, D. Buonfiglio, L.B. De Monte, A. Pileri, and F. Malavasi. 1994. Interaction between endothelium and $\mathrm{CD} 4{ }^{+} \mathrm{CD} 45 \mathrm{RA}^{+}$lymphocytes: role of the human CD38 molecule. J. Immunol. 154:952-959.

4. Deaglio, S., U. Dianzani, A.L. Horenstein, J.E. Fernandez, C. van Kooten, M. Bragardo, A. Funaro, G. Garbarino, F.D. Virgilio, J. Banchereau, and F. Malavasi. 1996. Human CD38 ligand: a $120-\mathrm{kDa}$ protein predominantly expressed on endothelial cells. J. Immunol. 156:727-734.

5. Deaglio, S., M. Morra, R. Mallone, C.M. Ausiello, E. Prager, G. Garbarino, U. Dianzani, H. Stockinger, and F. Malavasi. 1998. Human CD38 (ADPribosyl cyclase) is a counter-receptor of CD31, an Ig superfamily member. $J$. Immunol. 160:395-402.

6. Howard, M., J.C. Grimaldi, J.F. Bazan, F.E. Lund, L. Santos-Argumedo, R.M.E. Parkhouse, T.F. Walseth, and H.C. Lee. 1993. Formation and hydrolysis of cyclic ADP-ribose catalyzed by lymphocyte antigen CD38. Science. 262: 1056-1059.

7. Galione, A. 1993. Cyclic ADP-ribose: a new way to control calcium. Science. 259:325-326.

8. Funaro, A., A.L. Horenstein, L. Calosso, M. Morra, R.P. Tarocco, L. Franco, A. De Flora, and F. Malavasi. 1996. Identification and characterization of an active soluble form of human CD38 in normal and pathological fluids. Int. Immunol. 8:1643-1650.

9. Berthelier, V., F. Malavasi, G. Bismuth, C. Schmitt, and P. Deterre. 1996. Report on the 2nd international CD38 workshop. Res. Immunol. 147:407-411.

10. Umar, S., F. Malavasi, and K. Mehta. 1996. Post-translational modification of CD38 protein into a high molecular weight form alters its catalytic properties. J. Biol. Chem. 271:15922-15927.

11. Drach, J., S. Zhao, F. Malavasi, and K. Mehta. 1993. Rapid induction of CD38 antigen on myeloid leukemia cells by all trans-retinoic acid. Biochem. Biophys. Res. Commun. 195:545-550.

12. Zocchi, E., L. Franco, L. Guida, L. Calder, and A. De Flora. 1995. Selfaggregation of purified and membrane-bound erythrocyte CD38 induces extensive decrease of its ADP-ribosyl cyclase activity. FEBS (Fed. Eur. Biochem. Soc.) Lett. 359:35-40.

13. Mehta, K., U. Shahid, and F. Malavasi. 1996. Human CD38, a cell surface molecule with multiple functions. FASEB (Fed. Am. Soc. Exp. Biol.) J. 10: 1408-1417.

14. Thomas, J.D., P. Sideras, C.I.E. Smith, I. Vorechovsky, V. Chapman, and W.E. Paul. 1993. Colocalization of X-linked agammaglobulinemia and X-linked immunodeficiency genes. Science. 261:355-358.

15. Santos-Argumedo, L., F.E. Lund, A.W. Heath, N. Solvason, W.W. Wu, J.C. Grimaldi, R.M. Parkhouse, and M. Howard. 1995. CD38 unresponsiveness of xid B cells implicates Bruton's tyrosine kinase (btk) as a regular of CD38induced signal transduction. Int. Immunol. 7:163-170.

16. Kikuchi, Y., T. Yasue, K. Miyake, M. Kimoto, and K. Takatsu. 1995.
CD38 ligation induces tyrosine phosphorylation of Bruton tyrosine kinase and enhanced expression of interleukin 5-receptor alpha chain: synergistic effects with interleukin 5. Proc. Natl. Acad. Sci. USA. 92:11814-11818.

17. Yasue, T., H. Nishizumi, S. Aizawa, T. Yamamoto, K. Miyake, C. Mizoguchi, S. Uehara, Y. Kikuchi, and K. Takatsu. 1997. A critical role of Lyn and Fyn for B cell responses to CD38 ligation and interleukin 5. Proc. Natl. Acad. Sci. USA. 94:10307-10312.

18. Hoffman, T., R.J. Winchester, M. Schulkind, J.L. Frias, E.M. Ayoub, and R.A. Good. 1977. Hypoimmunoglobulinemia with normal T cell function in female siblings. Clin. Immunol. Immunopathol. 7:364-371.

19. Conley, M.E., and S.K. Sweinberg. 1992. Females with a disorder phenotypically identical to X-linked agammaglobulinemia. J. Clin. Immunol. 12: 139-143.

20. Malavasi, F., C. Milanese, M. Fabbi, P. Richiardi, F. Caligaris-Cappio, E. Ferrero, S. Roggero, P. Dellabona, and R. Ceppellini. 1984. Generation and characterization of murine monoclonal antibodies against HLA Class II molecules. Diagn. Immunol. 2:53-62.

21. Malavasi, F., F. Caligaris-Cappio, P. Dellabona, P. Richiardi, and A.O. Carbonara. 1984. Characterization of a murine monoclonal antibody specific for human early lymphohemopoietic cells. Hum. Immunol. 9:9-20.

22. Funaro, A., A.L. Horenstein, and F. Malavasi. 1995. Human CD38: a versatile leukocyte molecule with emerging clinical prospectives. Fund. Clin. Immunol. 3:101-114.

23. Spagnoli, G., C.M. Ausiello, A. Cassone, U. Casciani, G. Bellone, and F. Malavasi. 1987. Inhibitory effects of anti-HLA-A, B, C heavy chain and anti- $\beta_{2}$ microglobulin monoclonal antibodies on alloantigen and microbial antigeninduced immune responses "in vitro". Scand. J. Immunol. 25:555-565.

24. Peruzzi, L., G. Melioli, L.B. De Monte, M. Alessio, M. Zaccolo, S. Roggero, G. Bellone, A. Funaro, and F. Malavasi. 1989. Microplate selection technique (MPST): a new method for selecting mouse transfectants expressing human gene products. J. Immunol. Methods. 123:113-121.

25. Pelchen-Matthews, A., I.J. Parsons, and M. Marsh. 1993. Phorbol esterinduced downregulation of CD4 is a multistep process involving dissociation from $\mathrm{p} 56^{\mathrm{lck}}$, increased association with clathrin-coated pits, and altered endosomal sorting. J. Exp. Med. 178:1209-1222.

26. Greenwood, F.C., W.M. Hunter, and J.S. Glover. 1963. The preparation of ${ }^{131}$ I-labeled human growth hormone of high specific radioactivity. Biochem. J. 89:114-123.

27. Hager, D.A., and R.R. Burgess. 1980. Elution of proteins from sodium dodecyl sulfate-polyacrylamide gels, removal of sodium dodecyl sulfate, and renaturation of enzymatic activity: results with sigma subunit of Escherichia coli RNA polymerase, wheat germ DNA topoisomerase, and other enzymes. Anal. Biochem. 109:76-86.

28. Harlow, E., and D. Lane. 1988. Antibodies. A laboratory manual. Cold Spring Harbor Laboratory, Cold Spring Harbor, NY. 641-642.

29. Guida, L., L. Franco, E. Zocchi, and A. De Flora. 1995. Structural role of disulfide bridges in the cyclic ADP-ribose related bifunctional ectoenzyme CD38. FEBS (Fed. Eur. Biol. Soc.) Lett. 368:481-484

30. Graeff, R.M., T.F. Walseth, K. Fryxell, W.D. Branton, and H.C. Lee. 1994. Enzymatic synthesis and characterizations of cyclic GDP-ribose: a procedure for distinguishing enzymes with ADP-ribosyl cyclase activity. J. Biol. Chem. 269:30260-30267.

31. Funaro, A., L.B. De Monte, U. Dianzani, M. Forni, and F. Malavasi. 1993. Human CD38 is associated to distinct molecules which mediate transmembrane signaling in different lineages. Eur. J. Immunol. 23:2407-2411.

32. Funaro, A., M. Reinis, O. Trubiani, S. Santi, R. Di Primio, and F. Malavasi. 1998. CD38 functions are regulated through an internalization step. J. Immunol. 160:2238-2247.

33. Hoshino, S., I. Kukimoto, K. Kontani, S. Inoue, Y. Kanda, F. Malavasi, and T. Katada. 1997. Mapping of the catalytic and epitopic sites of human CD38/NADase to a functional domain in the carboxy terminus. J. Immunol. 158:741-747.

34. Kansas, G.S., G.S. Wood, and T.F. Tedder. 1991. Expression, distribution, and biochemistry of human CD39. J. Immunol. 146:2235-2244.

35. Di Rosa, G., M.J. Feito, M. Bragardo, G. Aversa, U. Dianzani, and F. Malavasi. 1997. CD39 and CD26 are associated with CD38 in human NK cells. J. Biol. Regul. Homeost. Agents. 11:12a. (Abstr.)

36. Deterre, P., L. Gelman, H. Gary-Gouy, C. Arrieumerlou, V. Berthelier, J.M. Tixier, S. Ktorza, J. Goding, C. Schmitt, and G. Bismuth. 1996. Coordinated regulation in human $\mathrm{T}$ cells of nucleotide-hydrolyzing ecto-enzymatic activities, including CD38 and PC-1. J. Immunol. 157:1381-1388.

37. Wang, T.F., and G. Guidotti. 1996. CD39 is an ecto- $\left(\mathrm{Ca}^{2+}, \mathrm{Mg}^{2+}\right)$-apyrase. J. Biol. Chem. 271:9898-9901.

38. Hurwitz, R., J. Hozier, T. LeBien, J. Minowada, K. Gajl-Peczalska, I. Kubonishi, and J. Kersey. 1979. Characterization of a leukemic cell line of the pre-B phenotype. Int. J. Cancer. 23:174-180.

39. Pegoraro, L., L. Matera, J. Ritz, A. Levis, A. Palumbo, and G. Biagini. 1983. Establishment of a Ph1-positive human cell line (BV173). J. Natl. Cancer Inst. 70:447-453.

40. Alessio, M., S. Roggero, A. Funaro, L.B. De Monte, L. Peruzzi, M. Geuna, and F. Malavasi. 1990. CD38 molecule: structural and biochemical analysis on human T lymphocytes, thymocytes, and plasma cells. J. Immunol. 145:878-884. 
41. Lee, H.C., E. Zocchi, L. Guida, L. Franco, U. Benatti, and A. De Flora. 1993. Production and hydrolysis of cyclic ADP-ribose at the outer surface of human erythrocytes. Biochem. Biophys. Res. Commun. 191:639-645.

42. Lund, F., N. Solvason, J.C. Grimaldi, R.M.E. Parkhouse, and M. Howard. 1995. Murine CD38: an immunoregulatory ectoenzyme. Immunol. Today. 16:469-473.

43. Oliver, A.M., F. Martin, and J.F. Kearney. 1997. Mouse CD38 is downregulated on germinal center B cells and mature plasma cells. J. Immunol. 158: 1108-1115.

44. Kinnon, C., S. Hinshelwood, R.J. Levinsky, and R.C. Lovering. 1993. $\mathrm{X}$-linked agammaglobulinemia-gene cloning and future prospects. Immunol. Today. 14:554-558.

45. Conley, M.E., O. Parolini, J. Rohrer, and D. Campana. 1994. X-linked agammaglobulinemia: new approaches to old questions based on the identification of the defective gene. Immunol. Rev. 138:5-21.

46. Conley, M.E. 1985. B cells in patients with X-linked agammaglobulinemia. J. Immunol. 134:3070-3074.

47. Conley, M.E., M.E. Fitch-Hilgenberg, J.L. Cleveland, O. Parolini, and J. Rohrer. 1994. Screening of genomic DNA to identify mutations in the gene for Bruton's tyrosine kinase. Hum. Mol. Genet. 3:1751-1756.

48. Yel, L., Y. Minegishi, E. Coustan-Smith, R.H. Buckley, H. Trubel, L.M. Pachman, G.R. Kitchingman, D. Campana, J. Rohrer, and M.E. Conley. 1996. Mutations in the $\mu$ heavy-chain gene in patients with agammaglobulinemia. $N$. Engl. J. Med. 335:1486-1493.

49. Nata, K., T. Takamura, T. Karasawa, T. Kumagai, W. Hashioka, A. Tohgo, H. Yonekura, S. Takasawa, S. Nakamura, and H. Okamoto. 1997. Human gene encoding CD38 (ADP-ribosyl cyclase/cyclic ADP-ribose hydrolase): organization, nucleotide sequence, and alternative splicing. Gene. 186:285-292.

50. Ferrero, E., and F. Malavasi. 1997. Human CD38, a leukocyte receptor and ectoenzyme, is a member of a novel eukaryotic gene family of nicotinamide adenine dinucleotide ${ }^{+}$-converting enzymes. J. Immunol. 159:3858-3865.

51. Prasad, G.S., D.E. McRee, E.A. Stura, D.G. Levitt, H.C. Lee, and C.D. Stout. 1996. Crystal structure of Aplysia ADP ribosyl cyclase, a homologue of the bifunctional ectoenzyme CD38. Nat. Struct. Biol. 3:1-8.

52. States, D.J., T.F. Walseth, and H.C. Lee. 1992. Similarities in amino acid sequences of Aplysia ADP-ribosyl cyclase and human lymphocyte antigen CD38. Trends Biochem. Sci. 17:495.

53. Munshi, C.B., K.B. Fryxell, H.C. Lee, and W.D. Branton. 1997. Largescale production of human CD38 in yeast by fermentation. Methods Enzymol. 280:318-330.

54. Gearing, A.J.H., and W. Newman. 1993. Circulating adhesion molecules in disease. Immunol. Today. 14:506-512.

55. Morra, M., M. Zubiaur, C. Terhorst, J. Sancho, and F. Malavasi. 1998. CD38 is functionally dependent on TCR/CD3 complex in human T cells FASEB (Fed. Am. Soc. Exp. Biol.) J. 12:581-592.

56. Zupo, S., E. Rugari, M. Dono, G. Taborelli, F. Malavasi, and M. Ferrarini. 1994. CD38 signaling by agonistic monoclonal antibody prevents apoptosis of human germinal center B cells. Eur. J. Immunol. 24:1218-1222.

57. Kumagai, M., E. Coustan-Smith, D.J. Murray, O. Silvennoinen, K.G. Murti, W.E. Evans, F. Malavasi, and D. Campana. 1995. Ligation of CD38 suppresses human B lymphopoiesis. J. Exp. Med. 181:1101-1110.

58. Cesano, A., S. Visonneau, S. Deaglio, F. Malavasi, and D. Santoli. 1998. Role of CD38 and its ligand in the regulation of MHC non-restricted cytotoxic T cells. J. Immunol. 160:1106-1115.

59. Yamashita, Y., K. Miyake, Y. Kikuchi, K. Takatsu, S. Noda, A. Kosugi, and M. Kimoto. 1995. A monoclonal antibody against a murine CD38 homologue delivers a signal to B cells for prolongation of survival and protection against apoptosis in vitro: unresponsiveness of X-linked immunodeficient B cells. Immunology. 85:248-255.

60. Vorechovsky, I., J.N. Zhou, L. Hammarstrom, C.I. Smith, J.D. Thomas, W.E. Paul, L.D. Notarangelo, and E. Bernatowska-Matuszkiewicz. 1993. Absence of xid mutation in X-linked agammaglobulinaemia. Lancet. 342:552.

61. Stashenko, P., L.M. Nadler, R. Hardy, and S.F. Schlossman. 1981. Expression of cell surface markers after human B lymphocyte activation. Proc Natl. Acad. Sci. USA. 78:3848-3852. 